Since about i 800 , however, a general interest in scientific questions has existed in nautical circles. Not only a small circle of practical men, as for instance those who belong to the Institute of Navigation, but many others who do not express their views are interested in scientific developments and follow them up. This general picture is not affected by an isolated instance of the use of an hour-glass in 1955 . Professor Taylor must be understood in this sense, and I share her view.

\title{
A Note on the Relative Wind
}

\section{from Captain Brett Hilder}

IN taking observations of the wind at sea, and in the study of the theory of airnavigation, it is often found difficult to give students a thorough conception of the relative (or apparent) wind. These notes are put forward to help instructors and others interested.

It is recorded that one of England's early Astronomers Royal went sailing on the Thames about 200 years ago, and what he learned that day made an advance in the science of astronomy. The Astronomer Royal was with some professional sailors, who must now be spiritual members of the Institute of Navigation. The learned gentleman was the Reỵerend Dr. James Bradley, who gave up his vicarage to become a professor of astronomy. The day in question had a wind of force four or five, but it was a steady wind, and the boat was tacking frequently.

At the masthead she wore a pennant, referred to by the doctor as a 'vane', and he noticed that it tailed away steadily enough down wind. But every time they went on to the other tack the direction of the pennant altered. The doctor was surprised that the wind should happen to alter every time they put about, but on mentioning this to the sailors he was told that the pennant only showed the direction of the relative wind, depending upon the direction and force of the true wind and the direction and speed of the boat, and their resultant changed every time they went about. How the sailors explained this without the aid of diagrams or algebra I don't know, but the doctor. went back to his study of the aberration of the stars with just the clue he needed to solve the puzzle.

Perhaps I should mention that this annual aberration of the stars is quite a small amount of angular displacement, and it is remarkable that the astronomers of those days could detect it with their comparatively crude instruments. The aberration is caused by the speed of the Earth in its orbit compared with the speed of light, giving a proportion of one part in about ro,000. This gives a minute angle of displacement, in the same way as 'angle of drift' in an aircraft, or 'leeway' for a ship at sea. While an average angle of drift might be $4^{\circ}$ for an aircraft, the angle is less than one minute of arc for aberration of a star.

Dr. Bradley's lesson in seamanship occurred about September i 728. During the next 200 years the pennants of ships continued to indicate the relative wind, except when they were at anchor, when the pennants would show the true wind. To be precise, the 'headwind' caused by the course and speed of the ship must be corrected to course made good and speed over the ground by 


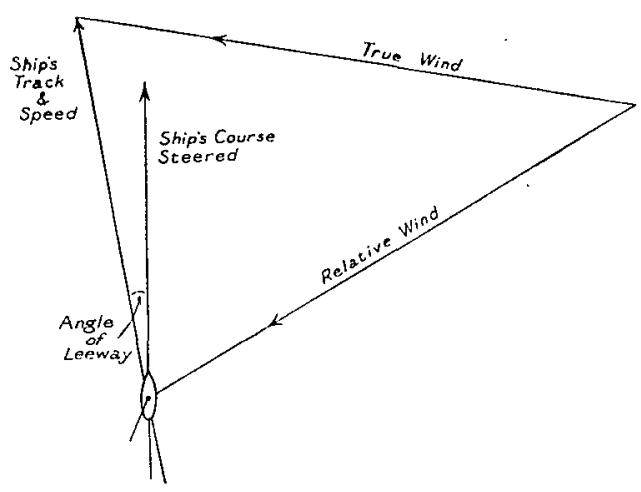

Fig. 1

allowing the leeway and any drift due to current. The simple diagram (Fig. I) should be memorized before we go any further.

Before dealing with the subject from the airman's point of view, we must deal with coal-burning steamships in their capacity as wind indicators. First let us take a ship at anchor in a steady wind, when we find that any smoke made will form a line downwind, and point in the direction in which it is going. Now coalburners have a habit of putting out a line of smoke at intervals depending upon the stoking of the fires. We therefore get the effect shown in Fig. 2.

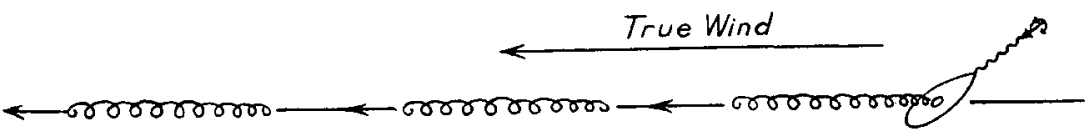

Fig. 2

When the coalburner is under-way she will have her smoke trailing downwind from the relative wind, and yet as each puff of smoke leaves the ship it can only be afterwards affected by the true wind. This is a puzzle to airmen, who are likely to see a case as shown in Fig. 3.

The solution to this problem is that the smoke from the ship is certainly travelling with the true wind alone, but each puff of smoke is created at different moments of time, and starts from a moving point. As a result the line of smoke from the ship is travelling straight downwind, but it is not pointing where it is going!

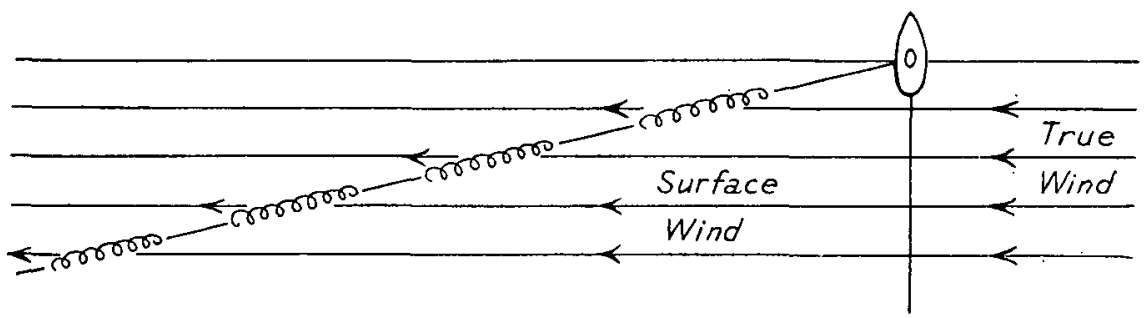

Fig. 3

Now an airman on reconnaissance can see the direction of the wind on the surface of the sea, and have a good idea of its force. The best type of atmosphere for our observations will be with a strong wind and an inversion at about I 000 feet, where the wind is probably the geostrophic one, in which case the 
smoke from the ship will be kept fairly horizontal, with less chance of rising vertically. Given the direction and speed of the true wind, and the direction of the relative wind as observed, it should be easy to determine the speed of the ship from her course. For with the knowledge of the directions of ship, true and relative winds, and the strength of the true wind, only one speed of the ship could fit the triangle (Fig. 4).

In the air the relative wind keeps remarkably hidden, for in spite of being always with us, it is hardly ever required in calculations. It does occur in some problems of patrol and reconnaissance, like the harmonic mean speed. For aircraft in flight there is no wind but the slipstream, the headwind caused by the course steered and the airspeed.

It might be thought that the track of the aircraft, being the resultant of aircraft velocity and wind velocity, should be the relative wind, but this is not so. To get the relative wind we have to reverse the course of the aircraft to get

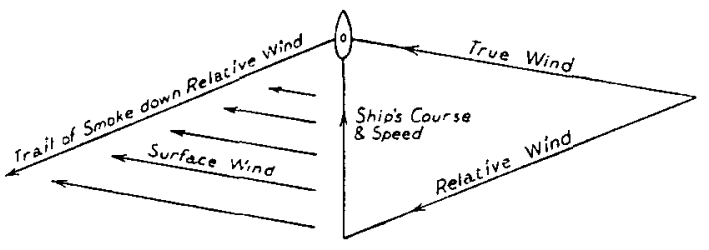

Fig. 4

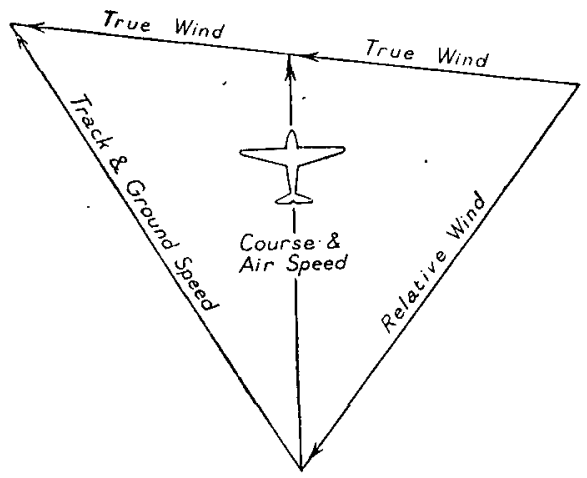

Fig. 5 the direction of the headwind caused, and it is the velocity of the headwind which has to be combined with the true wind to get the resulting relative wind (Fig. 5).

While these explanations may sound simple, they are often misunderstood by students. The experience of Dr. Bradley in 1728 is a pleasing example of the value of scientific collaboration as represented today by the Institute of Navigation. 